1. MBBS, FCPS

Assistant Professor \&

Incharge Obstetric \& Gynaecology Unit-II

Khairpur Medical College.

2. MBBS

Medical Officer Obstetric \&

Gynaecology Unit-II

Kausar Hospital Khairpur Mirs.

3. MBBS

Medical Officer

Department of Obstetric \&

Gynaecology Unit-II

Kausar Hospital Khairpur Mirs.

4. MBBS, FCPS

Professor

Professor \& Head Surgery

Civil Hospital Khairpur Mirs.

5. Third Year MBBS Student

Karachi Institute of Medical

Sciences

NUMS University.

Correspondence Address:

Dr. Bushra Begum Ramejo

Department of Obstetric \&

Gynaecology Unit-II

Khairpur Medical College.

dr.bushraramejo@gmail.com

Article received on:

07/07/2020

Accepted for publication:

22/09/2020

\title{
Frequency of common organisms causing vaginal discharge in sexually active women in reproductive age group.
}

\begin{abstract}
Bushra Begum Ramejo', Sanober Soomro², Sana Sadaf ${ }^{3}$, Khush Muhammad Sohu ${ }^{4}$, Mubashir Ahmed Ramejo ${ }^{5}$

ABSTRACT... Objective: To determine the frequency of organisms causing vaginal discharge. Study Design: Descriptive study. Setting: Department of Gynecology and Obstetrics Unit-II of Kausar Hospital Khairpur Mirs, Sindh. Period: 23rd, October 2019 to 22nd January 2020. Material \& Methods: Study population include sexually active females aged $18-45$ visiting to the OPD for complain of vaginal discharge. A complete history and examination was done for assessment of the patient for reproductive tract infections. Results: In one year time period 420 females reported to the OPD of the hospital. Out of total 1783 patients, $23.5 \%$ patients $(n=420)$ had complaint of vaginal discharge. Out of 420 patients enrolled in the study, $43.8 \%$ $(n=184)$ patients were diagnosed having non-infective vaginal discharge. Bacterial vaginosis had the highest prevalence among common reproductive tract infection estimating about $46.1 \%(n=109)$ cases. Conclusion: Multiple researches must be conducted on large scale to determine the actual ratio of reproductive tract infections in sexually active females. Furthermore awareness session should be delivered to the rural and urban population. Awareness to women regarding their sexual health and their positive influence on society should be given.
\end{abstract}

Key words: $\quad$ Reproductive Age Group, Sexually Active Women, Vaginal Discharge.

Article Citation: Ramejo BB, Soomro S, Sadaf S, Sohu KM, Ramejo MA. Frequency of common organisms causing vaginal discharge in sexually active women in reproductive age group. Professional Med J 2021; 28(1):86-89. https://doi.org/10.29309/TPMJ/2021.28.01.5470

\section{INTRODUCTION}

Among sexually active females, one fourth of women complain of vaginal discharge at some point in life. Vaginal discharge is a frequently reported complains in women of Asian region. ${ }^{1}$ According to surveys, approximately $20 \%$ of the global burden accounts for reproductive and sexual health. World Health Organization (WHO) has recommended treatment for five common reproductive tract infections including chlamydia, gonorrhea, trichomoniasis, candidiasis and bacterial vaginosis collectively if there is complain of vaginal discharge. Among these bacterial vaginosisand candidiasis occur dueto disturbance of normal flora of the vagina, whereas chlamydia trachomatis, gonorrhea and trichomoniasis are sexually transmitted infections. ${ }^{2}$ Reproductive morbidity in general comprises of three major categories comprising of contraceptive morbidity, obstetric morbidity and gynecological morbidity. Reproductive morbidity is affected by poverty and other socioeconomic factors other than biological reasons. Reproductive tract infections rank as the second most common cause of death in healthy young women. Over the years there has been increasing awareness about women's sexual health and its related morbidity. ${ }^{3}$ In developing countries studies focusing on prevalence of vaginal discharge in women of reproductive ages are evaluated. The etiology and risk factors favoring reproductive tract infections whether biosocial or biological are studied. ${ }^{4}$ Complications of sexually transmitted infections are devastating in women as compared to men. The most common RTI reported is vaginitis and the resulting etiology in $90 \%$ of cases is bacterial vaginosis, vaginal candidiasis and trichomoniasis. The most common etiology of vaginal discharge is bacterial vaginosis, occurring due to substitution of vaginal Lactobacilli with Gardnerella vaginalis and increased $\mathrm{pH}$. It is necessary to treat bacterial vaginosis as it raises 
the risk of pregnancy related mortality and risk of co-infection with other sexually transmitted infections. ${ }^{5}$ Vulvovaginal candidiasis is second frequent RTI caused by candida albicans, but the prevalence of non-candida albicans infection is increasing due to over use of low dose antimycotics. ${ }^{6}$ Trichomonas vaginalis is the most easily curable STI all over the world but its side effects are very harmful. Untreated trichomoniasis can cause infertility, neoplasia in cervix and higher risk of co-infection with HIV. Hence is the benefit of early diagnosis and treatment of trichomoniasis results in favorable long term effects. ${ }^{7}$ Presenting complains of vaginitis are vague and treatment is not based upon symptoms. The definitive treatment of RTI is based upon the etiology and it varies according to region and socioeconomic factors. In developing countries there have been very few studies conducted on etiology of RTI. Our study focuses on prevalence of reproductive tract infections in women of child bearing age and its etiopathogenesis.

\section{MATERIAL \& METHODS}

This is a descriptive study conducted in the department of Gynecology and Obstetrics Unit-II of Kausar Hospital Khairpur Mirs, Sindh. This study was carried out in collaboration with department of microbiology. Study population include sexually active females aged 18-45 visiting to the OPD for complain of vaginal discharge. All sexually active females visiting the OPD during the time period of 23rd October 2019 to 22nd January 2020 were selected for the study. Any female who has previously received any treatment for vaginal infections was extended from the study. A complete history and examination was needed for assessment of the patient for reproductive tract infections. An informed and written consent was taken from all female participants of the study. A predesigned Performa was used to collect information like age, marital status and socioeconomic status of participant. Patients was asked about consistency, odor, color of vaginal discharge, and other symptoms like dyspareunia, burning micturition and vulvar itching and pain. Vaginal examination was carried out by using speculum and its findings were noted. Samples were collected by dry cotton wool tipped swabs from vaginal fornixes. These were used for $\mathrm{pH}$ analysis, whiff test, gram staining and fungal cytology. Blood tests for detection of hepatitis $B, C$ and syphilis were performed. Participants of the study were ensured that their data would be kept anonymous. Data analysis was done to evaluate common symptoms of reproductive tract infections and its etiology.

\section{RESULTS}

During the time period of one year all sexually active females visiting the gynecology OPD for the complaint of vaginal discharge were selected. In three months period 400 females reported to the OPD of the hospital. Out of total 1783 patients, $22.43 \%$ patients $(n=400)$ had complaint of vaginal discharge. Out of 400 patients enrolled in the study, $44.75 \%(n=179)$ patients were diagnosed having non-infective vaginal discharge. Table-I shows the infectious etiology from the vaginal discharge. Bacterial vaginosis had the highest prevalence among common reproductive tract infection estimating about $49.32 \% \quad(n=109)$ cases, followed by candidiasis in $30.31 \%$ ( $n=$ $67)$, trichomoniasis in $8.14 \%(n=18)$ and mixed infections in $12.21 \% \quad(n=27)$ cases. Table-2 shows the symptoms of clinical presentation of reproductive tract infection. The most common presenting complain was found to be pain and it was present in $69.68 \%$ of participants.

\begin{tabular}{|l|c|c|}
\hline \multicolumn{1}{|c|}{ Infectious Etiology } & $\begin{array}{c}\text { Frequency } \\
\text { (N) }\end{array}$ & $\begin{array}{c}\text { Percentage } \\
\text { (\%) }\end{array}$ \\
\hline Bacterial vaginosis & 109 & $49.32 \%$ \\
\hline Candidiasis & 67 & $30.31 \%$ \\
\hline Trichomoniasis vaginalis & 18 & $8.14 \%$ \\
\hline Mixed infections & 27 & $12.21 \%$ \\
\hline \multicolumn{2}{|r|}{ Table-I. Infectious etiology n=221 } \\
\hline Clinical Presentation & $\begin{array}{c}\text { No. of Patients } \\
\text { (N) }\end{array}$ & $\begin{array}{c}\text { Percentage } \\
\text { (\%) }\end{array}$ \\
\hline Pain & 154 & $69.68 \%$ \\
\hline Itching & 72 & $32.57 \%$ \\
\hline Dysuria & 43 & $19.45 \%$ \\
\hline Dyspareunia & 37 & $16.74 \%$ \\
\hline Post-coital discharge & 27 & $12.21 \%$ \\
\hline
\end{tabular}

Table-II. Clinical presentation of reproductive tract infections $n=221$ 


\section{DISCUSSION}

Various studies conducted on prevalence of vaginal discharge in women showed that one fourth proportion of women had complain of vaginal discharge. Screening surveys in India came reported that it is the most frequently encountered reproductive health issue. ${ }^{8} \mathrm{~A}$ lot of women consider leucorrhoea as indication of vaginal infection but it is actually physiological discharge from vagina. Vaginal discharge associated with infection was most prevalent in the age group 26-35 years as these are the most important reproductive phase of a woman's life. Also females of this age are more concerned about their reproductive health as compared to women above 40 years old. ${ }^{9}$ In our study the most prevalent infection was found to be bacterial vaginosis followed by candidiasis. Frequent symptoms of vaginal infection include itching in the genital area, burning micturition, lower abdominal pain, dyspareunia and vaginal discharge. Lower abdominal pain is the most common presenting symptom accounting for $69.68 \%$ of cases followed by vulvar itching in $32.57 \%$ of patients. ${ }^{10}$ Dysuria is not recognized by women as a symptom of vaginal infection commonly. In our study it is the presenting complain $19.45 \%$ of cases whereas in UK around $30 \%$ of complain of dysuria is due to sexually transmitted infections. Trichomoniasis is a devastating STI as it can remain undiagnosed for years and can be transmitted sexually. Trichomoniasis also increases the chances of HIV co-infection hence making it the most common non-viral sexually transmitting disease. In our study vaginal discharge is found to be pathological in $12.21 \%$ of cases whereas $48.5 \%$ complained of discharge which was physiological in nature. Normal vaginal $\mathrm{pH}$ is in the range of 3.8 and 4.4. The most common reported cause of vaginal discharge is vulvovaginal candidiasis but the most common reported RTI in our study is bacterial vaginosis. Other common causes of vaginal discharge are Neisseria gonorrhea, chlamydia trachomatis and pelvic inflammatory disease. Multiple sexual partners is the most commonly associated factor with bacterial vaginosis as less cases are reported in monogamous relationships. As we have higher incidence of bacterial vaginosis in our population, it accounts for possible abortion and pre-term deliveries. Few studies have linked vaginal discharge with previous abortion, home deliveries and high parity of woman. Child delivery at home by Daialso increases chances of reproductive tract infections in rural areas. Increased ratio of vaginal infections is also reported in females having intrauterine contraceptive device as compared to females not having it. ${ }^{11}$ A survey was conducted in females of rural areas comparing the ratio of $\mathrm{RTI}$ in females using oral contraceptive pills or surgical sterilization as contraception. It concluded that females using oral pills are less exposed to causative organism whereas surgical sterilization in rural setups may provide a pathway for RTI. ${ }^{12}$ Awareness among women of rural areas is important to avoid long term complications and provide a better health. Socioeconomic factors have also played an important role in female sexual health as low income and strong sexual desire can lead to increased chances of RTI. ${ }^{13}$ The risk factors for bacterial vaginosis and candidiasis is not known, however few studies have correlated it to previous abortions, weak immune system and excessive antibiotic treatments. Trichomoniasis is more prevalent in lower socioeconomic class, hence it had greater prevalence in developing countries. Positive correlation was found in patients having abortions before the age of 30 years and increased risk of candidiasis and bacterial vaginosis. ${ }^{14}$ Healthier sexual health of females has a positive impact on their confidence and mental health. Creating awareness amongst community and self-reporting of infection must be instilled into females. Reducing reproductive morbidity and mortality has positive influence on society and eventually better lifestyle. Surveys are conducted across the countries but the major hurdle along the way is small sample size and selection bias.

\section{CONCLUSION}

We concluded awareness session should be delivered to the rural and urban population. Awareness to women regarding their sexual health and their positive influence on society should be given. Multiple researches must be conducted on large scale to determine the actual ratio of reproductive tract infections in sexually 
active females.

Copyright@ 22 Sep, 2020.

\section{REFRENCES}

1. Patel V, Pednekar S, Weiss $H$, Rodeigues M, Barros $P$, Nayak B, et al. Why do women complain of vaginal discharge? A population survey of infectious and psychological risk factors in a South Asian community. Int J Epidemiol. 2005; 34:853-62.

2. Reproductive health strategy to accelerate progress towards the attainment of international development goals and targets. World Health Organization. 2008. WHO/RHR/04.8.

3. Dixon-Mueller R, Wasserheit J. The culture of silence: Reproductive tract infections among women in the third world. In Dixon -Mueller R Wasserheit J. eds. A study New York: International Women's Health Coalition. 1991.

4. Agrawal M, Nigam N, Goel R, Goel JK, Shukla M. Etiopathogenesis of vaginal discharge among married women in reproductive age group residing in rural area of Bhojipura District, Western Uttar Pradesh, India. International Journal of Reproduction, Contraception, Obstetrics and Gynecology.;8(7):2599.

5. Madhivanan P, Krupp K, Chandrasekaran V. Prevalence and correlates of bacterial vaginosis among young women of reproductive age in Mysore, India. Indian J Med Microbiol 2008; 26(2):132-7.

6. Sobel JD. Vulvovaginal candidosis. The Lancet 2007; 369(9577):1961-71.
7. Olowe O, Makanjuola O, Olowe R, Adekanle D. Prevalence of vulvovaginal candidiasis, trichomoniasis and bacterial vaginosis among pregnant women receiving antenatal care in Southwestern Nigeria. Eur J Microbiol Immunol 2014; 4(4):193-7.

8 Singh AJ. Vaginal discharge: Its causes and associated symptoms as perceived by rural north Indian women. Indian J Community Med. 2007; 32:226.

9. Dean AG, Arner TG, Sunki GG, Friedman R, Lantinga M, Sangam S, et al. Epi Info ${ }^{\text {TM }}$, a database and statistics program for public health professionals. $C D C$, Atlanta, GA, USA; 2011.

10. Tanksale VS, Sahasrabhojanee, Patel V, Nevreker P, Menezes S, Mabey $D$. The reliability of a structured examination protocol and self-administered vaginal swab: A pilot study of gynaecological outpatient in Goa, India. Sex Transm Infect. 2003; 79:251-3.

11. Sharma AK, Ranjan R, Mehta G. Prevalence and determinants of reproductive tract infection among women. J Commun Dis. 2004; 36(2):93-9.

12. Pant B, Singh JV, Bhatnagar M, Garg SK, Chopra H, Bajpai SK. Social correlates in reproductive tract infections among married women in rural area of Meerut. Indian J Community Med. 2008; 33(1):52-3.

13. Sharma AK, Ranjan R, Mehta G. Prevalence and determinants of reproductive tract infection among women. J Commun Dis. 2004; 36(2):93-9.

14. Sharma AK, Ranjan R, Mehta G. Prevalence and determinants of reproductive tract infection among women. J Commun Dis. 2004; 36(2):93-9.

\begin{tabular}{|c|c|c|c|}
\hline \multicolumn{4}{|c|}{ AUTHORSHIP AND CONTRIBUTION DECLARATION } \\
\hline Sr. \# & Author(s) Full Name & Contribution to the paper & Author(s) Signature \\
\hline 1 & Bushra Begum Ramejo & $\begin{array}{l}\text { Conception and design, } \\
\text { Statistical expertise. }\end{array}$ & \\
\hline 2 & Sanober Soomro & $\begin{array}{l}\text { Critical revision of the article } \\
\text { for important intellectual } \\
\text { content. }\end{array}$ & \\
\hline 3 & Sana Sadaf & Data collection. & \\
\hline 4 & Khush Muhammad Sohu & $\begin{array}{l}\text { Data collection, Critical } \\
\text { revision, Drafting of the article }\end{array}$ & \\
\hline 5 & Mubashir Ahmed Ramejo & Data collection. & Musser \\
\hline
\end{tabular}

